\title{
O Espelho dos Reis (1341-1344) de Frei Álvaro Pelayo: alguns apontamentos sobre identidade, história e cultura
}

\author{
Leonardo Girardi ${ }^{1}$
}

Resumo: O presente artigo tem como objetivo a análise do tratado de Frei Álvaro Pelayo nomeado "Espelho dos Reis", composto entre os anos de 1341-1344 e dedicado ao soberano de Castela Alfonso XI. Nele, temos a intenção de ir além das questões políticas (a obra em si é um tratado de teoria política) e refletir sobre a identidade em relação a outros temas visíveis na obra do Frei galego, com a história e a cultura, pensando em elementos que envolvem a centralização do poder régio e a defesa da teocracia pontifícia, próprios do lugar de Álvaro na história e das suas intenções políticas.

Palavras-chave: Baixa Idade Média; Península Ibérica; Álvaro Pelayo; Espelho dos Reis; Identidade.

Resumen: El presente articulo tiene como meta el análisis del tratado de Fraile Alvaro Pelayo nombrado "Espejo de los Reyes", compuesto entre los años 1341-1344 y dedicado al rey de Castilla Alfonso XI. En el, tenemos la intención de ir más alla de las cuestiones de política (la obra en si es un tratado de teoría política) y reflexionar sobre la identidad en relación a otros temas visibiles en la obra del fraile gallego, como la historia y la cultura, considerando los elementos que implican en la centralización del poder regio y la defensa de la teocracia pontificia, propios del lugar de Alvaro Pelayo en la historia y de sus intenciones politicas.

1 Graduado em História pela Universidade Federal do Paraná e mestrando do Programa de Pós-Graduação em História pela mesma instituição. E-mail para contato: leon.historia05@gmail.com. 
Palabras clave: Baja Edad Media; Peninsula Iberica; Alvaro Pelayo; Espejo de los Reyes; Identidad.

Álvaro Pelayo, hispano. Eis uma identificação que aparece logo nas saudações do autor ao soberano de Castela, usadas para abrir a obra de sua autoria que elegemos como fonte para conduzir nossas próximas reflexões, o Espelho dos Reis (Speculum Regum) composição elaborada entre os anos de 1341 e $1344^{2}$. A pequena palavra atribuição própria de Álvaro, o que por si só já é relevante - tem chances enormes de passar despercebida diante de olhos desatentos ou, absorto por outras indagações; entretanto, devidamente apreendida, examinada e refletida pode sugerir em meio a grande tessitura do plano social, político, religioso e cultural no qual o frade menorita está inserido, uma clara ideia de identidade - ou melhor colocando em vista de todo este ambiente, identidades.

A partir deste breve esboço é possível que captemos uma miríade de traços, detalhes muitas vezes sutis, que hão de caracterizar e imprimir certas expressões capazes de diferenciar um indivíduo ou grupo de indivíduos através dos mais variados planos da experiência humana. E estas caracterizações vão além da simples distinção entre

\footnotetext{
${ }^{2}$ PAIS, Álvaro. O Espelho dos Reis (Speculum Regum). Vol. I-II. Lisboa: Instituto de Alta Cultura, 1955-1963.
} 
grupos, povos: como veremos no caso de Frei Álvaro, tal elemento identitário - o ser hispano - pode resultar numa boa ferramenta no que tange ao momento histórico em que vive, sua orientação política e suas intenções: como um representante da teocracia pontifícia em seu momento de declínio, Álvaro tenta resistir ao avanço do poder régio castelhano e português segurando a bandeira pontifícia, usando como meio para esta finalidade algo como uma "propaganda" que atraia os ibéricos a seu propósito... Qual a maneira mais adequada para fazer isso? Reunir todos os cristãos da região sob uma égide apenas, um único rei que tenha um vínculo não só de alianças e acordos, mas histórico e cultural? Talvez aqui o pequeno termo hispano seja um instrumento essencial por agregar este grande número de indivíduos num mesmo passado, romano, a quem o rei de Castela historicamente sucede. Temos em nossas mãos uma das facetas das quais o Frade poderia se valer para seus intentos, uma das possíveis identidades que lhe teria utilidade.

É neste sentido, portanto, que buscaremos explorar brevemente tal elemento identitário coligando-o com dois temas, História e Cultura - dois braços fortes (dentre outros, claro) da sociedade medieval latina, capazes de nos revelar, mesmo que de forma sintética, a ampla gama de dados que podemos extrair sobre o tema da(s) identidade(s) a partir de uma composição da primeira metade do século XIV, segunda num conjunto maior de três grandes trabalhos do autor, destinada por Álvaro 
Pelayo à orientação do soberano castelhano Alfonso XI mas, aventando hipóteses, dedicada de igual maneira ao rei lusitano Afonso IV com quem o menorita, também Bispo de Silves (atual Faro, Portugal) nutriu algumas desavenças.

\section{História e identidade: A cruzada em terras visigóticas}

Para iniciarmos nossas reflexões, partamos de um marco localizado um ano após o término da redação do Espelho dos Reis. A data é 1345; Afonso IV de Portugal e Alfonso XI novamente encontram-se em desavença. Entretanto, a querela não assume contornos tão graves quanto aquela iniciada em 1336 e que encontrou seu termo somente em 1339, opondo-os em armas por conta de um matrimônio infeliz e outros desentendimentos ${ }^{3}$. O embate de então se faz através da pena e do papel, diplomaticamente, e adianta em várias décadas as disputas que irão marcar a descoberta de novos mundos, cujo bom exemplo pode ser o Tratado de Tordesilhas assinado em $07 \mathrm{de}$ junho de 1494.

A 15 de novembro de 1344, por uma bula expedida pelo Papa Clemente VI, o Conde de Clermont Luís de La Cerda consegue se fazer investido do senhorio das Ilhas Afortunadas e recebe o título de

3 SOUZA, Armindo de. "1325-1480”. In: MATTOSO, José (dir.). História de Portugal: A Monarquia Feudal (vol. II, 1096-1480). Lisboa: Editorial Estampa, 1993. 
"Príncipe da Fortuna". Tal fato chama a atenção do soberano português, dirigindo uma carta ao pontífice - datada de 12 de fevereiro de 1345 - a quem reclama, por conta de uma expedição empreendida anos atrás e pelo direito de descoberta, tal possessão em mar aberto (muito embora ceda-as ao príncipe por questões de consanguinidade) ${ }^{4}$. O rei castelhano também dirige uma carta ao Papa (13 de março de 1345), reconhecendo o título de Luís de La Cerda, mas, alega a pertença das Ilhas Afortunadas à sua Coroa, sendo através duma série de sentenças, a que mais se destaca é a justificativa de que como herdeiro dos visigodos, as Ilhas the pertencem (“[...] ac quod acquisitio regni africe ad nos nostrumque ius regium nullumque alium dinosscitur pertinere...”5). A disputa em si, bem como sua conclusão não nos interessa; evocamos, entretanto, esta passagem justamente por evocar dois elementos caros ao que nos propomos pensar - desta, portanto, gostaríamos de aproveitar a questão da terra e da herança que estão envolvidas na arguição do soberano de Castela.

Segundo Joseph F. O'Callaghan, o argumento retirado para tal alegação de descoberta do que hoje são as Ilhas Canárias parte de Álvaro Pelayo, advindo justamente do início do Espelho dos Reis onde

\footnotetext{
${ }^{4}$ Comissão Executiva das Comemorações do V Centenário da Morte do Infante D. Henrique. Monumenta Henricina (vol. I). Coimbra: Atlandida, 1960, pp. 230-234.

${ }^{5}$ Idem, pp. 234-235. O mesmo argumento, décadas após, será usado por Alfonso de Cartagena em 1437 para alegar a posse das Ilhas Canárias.
} 
o frade menor evoca a ancestralidade visigótica ${ }^{6}$. O uso, portanto, desta "herança" é uma das chaves de nossa reflexão: como a questão das Canárias não era o foco de Álvaro, outra, bem mais próxima do contexto de redação da obra pode corroborar com a hipótese de uma identidade esboçada pelo frade, unindo o soberano de então, Alfonso XI, aos antigos habitantes da Península enquanto dá substância e legitimidade a seu discurso (ou uma parte dele, afinal o Espelho dos Reis, obra do gênero dos espelhos de príncipe ${ }^{7}$ vai mais além no tocante as intenções do autor, conforme destacamos na introdução de nosso

${ }^{6}$ O’CALLAGHAN, Joseph F. La cruzada de 1309 em el contexto de la Batalla del Estrecho. In: Medievalismo, 19, 2009, p. 246 e, The Gibraltar Cruzade: Castile and the Battle for the Strait. Philadelphia: University of Pennsylvania Press, 2011, pp. 210-211. Muito embora o autor aparente lançar o dado como fato, gostaríamos de pensá-lo como hipótese, já que não há indicativos claros de que Alfonso XI tenha lido a obra do frade.

${ }^{7}$ A princípio, as obras que compõem este gênero têm como ideia base a orientação de um príncipe através do reto caminho, orientando-o pelas virtudes e os bons exemplos (todos cristãos, obviamente) para que este possa desenvolver um bom governo e conduzir seus súditos à bem aventurança eterna. Entretanto, como é o caso do próprio do Espelho dos Reis e tantos outros mais, seus redatores - normalmente clérigos buscam instruir o soberano no sentido de conter o seu poder, de forma que não extrapole aquilo que cabe a sua própria esfera, secular. A contrapartida régia vem da seguinte forma de acordo com o que podemos observar no dito de Fátima Regina Fernandes: "[...] No entanto, esses mesmos materiais doutrinais depois de glosados e atualizados seriam utilizados pelos reis como instrumento de cristalização de uma imagem modelar régia. [...]" - esta imagem, projetada então para a sociedade política e todo o restante do corpo dos súditos ressaltaria a figura régia, dando ao rei ainda mais força no poder. FERNANDES, Fátima Regina. Teorias políticas medievais e a construção do conceito de unidade. In: História. São Paulo, no 28 (2), 2009, p. 52. Ver também NOGALES RINCÓN, David. Los espejos de príncipes en Castilla (siglos XIII-XV): un modelo literario de la realeza bajomedieval. In: Medievalismo: Boletin de la Sociedad Española de Estudios Medievales. Ano 16, no 16. Madrid, 2006, pp. 09-39. 
texto: resistir ao avanço régio, defender a teocracia pontifícia) - que visa justamente a continuidade de uma cruzada contra os muçulmanos com quem o rei vinha batendo-se na região sul do reino.

A esta herança mencionada acima, podemos coligar o fator do espaço, da terra, que juntos são capazes de perfilar verdadeiramente uma verdadeira identidade, através da qual o menorita lançará seus argumentos: "[...] ao ilustre e ínclito Afonso, generosíssimo e vitoriosíssimo rei dos Visigodos, vigário terrestre de Cristo na província da Bética e terras circunjacentes, e nos dilatados reinos de Espanha $[\ldots]^{\prime 8}$ e principalmente,

De direito é-te devida a África, onde outrora era sinceríssimamente respeitado o nome de Cristo, e que hoje é habitada por Maomé. Submeteram-na à fé os reis dos Godos, teus ascendentes, gloriosíssimos e fidelíssimos na fé de Cristo. Agora, detêem-na e ocupam-na, por causa dos nossos pecados, os inimigos da fé e teus. [...] Restitui essa terra, pelo direito pós-limíno [...]. Possui-a como às outras terras hespéreas. Ela pertence-te por direito hereditário. E porque te pertence, submete-a à fé, ocupa-a em nome de Cristo, e vinga a ofensa contra Ele cometida. [... $]^{9}$

${ }^{8}$ PAIS, Álvaro. Op. Cit., Vol. I, p. 05. Nas próximas menções à obra, faremos a indicação através da abreviatura EdR.

${ }^{9}$ EdR, Vol. I, p. 13. 
Observa-se a partir destes dois extratos da fonte, primeiramente, o domínio de Álvaro em matéria de história (o que contribui ainda mais para o caracterizarmos como Homem de Saber, outra faceta identitária a que iremos abordar através do eixo Cultura/ Identidade logo em seguida) e, em segundo, o uso desta que o frade faz no intento de construir toda uma argumentação que torna legitima a empresa de Alfonso XI, sobretudo no que tange ao pedido de apoio por parte da Santa Sé para a caracterização de "cruzada" da campanha empreendida pelo soberano de Castela contra os muçulmanos de Granada e Marrocos.

Assim, usando-se de Isidoro de Sevilha e outros autores, a linhagem da qual provém Alfonso XI (que de certa forma é de um ramo ilegítimo dada a usurpação de Fernando IV, gerando todo o problema com os infantes de La Cerda) é remontada até os visigodos tardoantigos que, até a vitória muçulmana na Batalha do Guadalete $(711)^{10}$ controlavam extensas faixas de terra da Península Ibérica, compondo o Reino Visigodo de Toledo - neste sentido, é interessante que Álvaro use a separação provincial romana vigente na época para a composição peninsular de então, vinculando ainda mais o soberano com aquele passado. Se pensarmos estes dados juntamente com as raízes da

\footnotetext{
${ }^{10}$ FRIGHETTO, Renan. Hispania Misera Effecta: a Batalha do Guadalete (711) e a passagem da Antiguidade Tardia à Idade Média. In: GUIMARÃES, Marcella Lopes. Por São Jorge! Por São Tiago! Batalhas e narrativas ibéricas medievais. Curitiba: Editora da UFPR, 2013, pp.19-48.
} 
Reconquista, ou seja, os povos astúres e demais do norte peninsular alegando-se "herdeiros" do reino visigodo e, portanto, detentores verdadeiros das terras "roubadas" pelos berberes" ${ }^{11}$, vemos Álvaro aproveitando-se de um discurso já histórico para legitimar sua própria empresa.

A "identidade visigótica" que Alfonso XI carrega ganha mais destaque no momento em que observamos as "pontes" estabelecidas entre o presente e o passado quando o frade caracteriza os visigodos como "gloriosíssimos e fidelíssimos na fé de Cristo" e os iguala aos castelhanos - sobretudo seu rei - como sendo também grandes defensores da ortodoxia... Talvez até mesmo os principais de toda a Cristandade (algo que Álvaro, priorizando principalmente a figura do soberano, ressalta ao longo de sua obra). O combate ao infiel, ao lado da defesa da ortodoxia, são traços importantes dessa identidade; Álvaro traz exemplos destes dois elementos ao ligar os seguintes reis do passado à genealogia de Alfonso XI:

Igualmente, senhor, ofereceram a Deus, em sua sacratíssima vida, estas três dádivas os santos reis teus ascendentes, que houve em Espanha, como o príncipe dos godos, o religiosíssimo Sisebuto [...] e Hermigelo [...] morto no cárcere em dia de Páscoa, pela fé de Cristo, por seu pai que era herege ariano; e Ricardo, seu irmão, de que fala a Legenda de S.

${ }^{11}$ LOMAX, Derek William. La Reconquista. Barcelona: Crítica, 1984. 
Leandro, o qual extirpou da Espanha toda a heresia dos arianos e aumentou o culto da fé; e S. Fernando, teu tetravô, que trouxe à fé da Santa Madre Igreja, Sevilha com outras terras, a qual estivera ocupada pelos maométicos quase desde o tempo de seus bispos S. Leandro e Santo Isidoro. ${ }^{12}$

Ademais, ao ser evocado o nome de Fernando III vemos novamente a questão da terra aparecer (por meio das conquistas do soberano das quais Álvaro até menciona Sevilha, a qual seu bispado em Silves está submetido), fator de grande importância conforme já destacado para pensar uma identidade - ainda mais quando unida aos outros aspectos levantados. A confluência destes elementos na imagem de Alfonso XI resulta numa identidade que sem dúvida há de ser compartilhada pelos demais súditos de sua coroa, dado que o espelho que Álvaro escreve serve para guiar não só o rei como tantos outros... Além do que, o soberano deve ser o espelho em que suas gentes devem se espelhar. Assim, pensando um pouco além daquilo que nos propomos, a formação de uma identidade comum auxilia justamente na luta e defesa da nação hispana a que Álvaro se diz pertencer (de acordo com a abertura de nosso texto), esta sendo carregada de uma tradição e de um passado mui rico e principalmente, legítimo. Como herdeiros dos visigodos, a defesa e conquista das terras que por direito lhes pertencem é completamente válida, justificando portanto uma cruzada.

\footnotetext{
${ }^{12}$ EdR, Vol. I, p. 33.
} 
Neste sentido, é interessante o frade recorrer a duas explicações de ordem claramente jurídica, conforme podemos ver no primeiro extrato trazido neste texto: o direito póslimínio e o direito de hereditariedade. Deste segundo, pudemos deixar mais do que clara a sua explicação - pela linhagem, Alfonso XI é descendente dos reis visigodos. Já a proposta do primeiro corrobora justamente no ato de pegar em armas contra o infiel e significa o seguinte: "retomada, por parte de um Estado vencido na guerra, e em face de um tratado de paz, das parcelas de seu território ocupadas anteriormente por outro Estado, vencedor"13 - por ambas as vias de direito, as terras visigóticas são do soberano castelhano.

Desta forma, vemos a integração da terralespaço com a herança, podendo-se agregar a esta última elementos de uma tradição (pensando no cristianismo ortodoxo que vem da conversão de Recaredo no III Concílio de Toledo em 589, que o último extrato acima ressalta e que segue até os dias de Álvaro Pelayo) no sentido de definir uma identidade a que Alfonso XI se vincula e por extensão, todos os seus súditos, incluindo o próprio Álvaro - atuando como um elemento legitimador de uma empresa que já vinha-se sendo conduzida, ou seja, a cruzada contra os muçulmanos. A história age então como fornecedora da matéria-prima a qual o frade menorita irá se aproveitar para realizar

\footnotetext{
${ }^{13}$ Definição esta que extraímos de http://www.dji.com.br/internacional/posliminio.htm (consultado em 21/03/2014).
} 
tamanha prefiguração, encontrando suporte, sobretudo, nas vozes de autoridade as quais ele recorre e domina - uma das matérias do tópico seguinte.

\section{Cultura e identidade: um novo rei para novos tempos - alguns elementos necessários à figura régia}

A conjuntura de 1200/1300, justamente onde estão inseridos estes personagens e toda esta gama de elementos, aponta para mudanças bastante visíveis na estrutura da Cristandade Latina - senão, em todo o espaço do mundo conhecido, seja entre os muçulmanos, seja entre os romanos do oriente. Outono da Idade Média ou, primavera dos tempos modernos ${ }^{14}$ ? A resposta dependerá muito do ponto de vista de cada medievalista. Entretanto, corroboramos com o pensamento de Marcella Lopes Guimarães $^{15}$ e acreditamos que, mesmo apontando para uma nova estrutura, a trama de fins do medievo - ou, para referenciar um balizamento mais rígido e estrito, a "Baixa Idade Média" - é essencialmente medieval.

\footnotetext{
${ }^{14}$ Para nos aproveitarmos do título de duas grandes obras a respeito da transição do Medievo para a Era Moderna, respectivamente de Johan Huizinga e Phillip Wolff.

${ }^{15}$ GUIMARÃES, Marcella Lopes. Cultura na Baixa Idade Média. In: GIMENEZ, José Carlos (Org.). História Medieval II: A Baixa Idade Média. Maringá: EDUEM, 2010, v. II p. 113-136, p. 116.
} 
O que queremos dizer com tal colocação? Que em muitos casos, são buscados traços que identifiquem ou se aproximem do Renascimento, da Era Moderna; seja no tocante a política, através da formação de um Estado que dá indícios de burocratização ou na cultura, como o fizera Jacob Burckhardt em seu célebre "A Cultura do Renascimento da Itália ${ }^{16 "}$ ou também Norbert Elias, em "O Processo Civilizador" - este último, destacando aqui, por frisar alguns elementos de ordem comportamental/cultural que indiciam tal transição ${ }^{17}$. Em suma, olvida-se de se visualizar o recorte cronológico dentro de toda a dinâmica que ele compreende em detrimento de buscar, as vezes, meras justificativas para dar embasamento a um período subsequente, mais complexo e "desenvolvido" deixando e lado um período rico e fértil que merece a devida atenção para o que ainda estava em processo, há muitos passos até de atingir uma conclusão.

Longe de almejarmos tecer críticas às obras acima citadas, gostaríamos de usá-las como mote para dar prosseguimento às reflexões que já estamos desenvolvendo acerca das identidades, usando-as para pensar estes homens do outono da Idade Média (imbuídos de uma larga tradição, como pudemos ver mesmo que rapidamente logo acima) como

\footnotetext{
${ }^{16}$ BURCKHARDT, Jacob. A cultura do Renascimento na Itália: um ensaio. Brasília, DF: Ed. da UnB, 1991.

${ }^{17}$ ELIAS, Norbert. O processo civilizador: formação do Estado e civilização. Rio de Janeiro: Zahar, 1993, pp. 193-249.
} 
medievais propriamente, muito embora estejam a um passo da modernidade.

Como a cultura fora usada muitas vezes por estes e outros historiadores para dar forma e sustento às suas teses, a coligaremos à questão da identidade no sentido de explorarmos melhor a conjuntura que já destacamos- eventualmente extrapolando para outros reinos latinos importantes para que possamos estabelecer algumas relações e, gerar alguns contrastes. A cultura a que nos referimos necessariamente é aquela que o Espelho dos Reis nos permite vislumbrar, por consequência, das elites: o pouco que sabemos sobre o populus parte de vestígios e dados deixados por tal estamento... Tomando em conta também que pretendemos pensar a respeito de segmentos da realeza e do clero para o prosseguimento destas reflexões.

Retomemos, pois um longo evento que tivemos a oportunidade de citar, mas não se deter: a Reconquista. Em suma, este foi um movimento iniciado a partir de núcleos cristãos localizados ao norte da Península Ibérica com o objetivo de retomar as terras do sul que outrora compunham o reino visigótico, arrebatado a partir de 711 pelos muçulmanos ${ }^{18}$. No século XIII ela estava já esgotada, apesar da existência do reino de Granada como último reduto árabe. Monarquias forjadas no calor da batalha, homens cujo ofício era as armas, necessitavam se readequar. Começa-se assim, lentamente, um esforço

${ }^{18}$ FRIGHETTO, Renan, op. cit.; LOMAX, Op. Cit. 
interno de cada reino para se ordenar política e teoricamente, consolidando o que fora obtido por meio da força. Observa-se nesta conjuntura então a elaboração de largas obras de espécie legislativa, como a de D. Alfonso X, o Sábio, rei de Castela (Las Siete Partidas, aplicada apenas anos mais tarde com seu bisneto, Alfonso XI) ou de D. Afonso III de Portugal e seus sucessores (D. Dinis, Afonso IV, etc.) acorrendo justamente neste sentido. Esta é a "era dos reis legisladores" - um claro indicativo de mudanças na Península Ibérica e um marco artificial (como a própria Idade Média o é, pelo menos em seu termo de balizamento) que traduz algo importantíssimo que estava em movimento: a mesma centralização do poder régio que Álvaro luta contra.

Tal fenômeno, a centralização do poder, não é particular da conjuntura ibérica: observa-se também em outros espaços da Cristandade latina como Inglaterra e França. Neste último reino, é interessante destacar a própria figura de Luís IX, feito santo em 1297 e que por suas políticas revela muito bem a empresa de que falamos - a alçada da figura régia bem como de toda a realeza, o estabelecimento de um ritual particular, original, de sagração que o coloca numa posição (pelo menos teórica, de acordo com a proposta franca) superior aos demais monarcas cristãos, representado pela alcunha de rex 
christianissimus $^{19}$. É claro que o processo político que conduz estas outras monarquias a tal ponto de desenvolvimento não é o de Reconquista. As estratégias, embora distintas, levam-nas a um ponto similar que exigirá quase que a mesma posição do rei diante do reino e de sua sociedade política, também dos súditos num âmbito maior. E neste momento, a cultura faz-se como um elemento comum a todos. Voltemos então à Península Ibérica.

Muito embora o esforço maior da Reconquista já não seja mais necessário, a luta deve continuar - é um elemento que caracteriza estes homens, o combate ao infiel é o que lhes move, como bem podemos atestar por estas outras palavras de Álvaro Pelayo que reforçam a "cruzada" por ele pregada e que já tivemos a oportunidade de nos remeter:

Não acredites, prudentíssimo rei, nas suas condições e promessas de paz, porque os inimigos de teu Deus e Senhor não podem ser teus amigos. Como poderá ser fiel aos homens, aquele que foi infiel a Deus? (Causa II, questão VII, cap. No potest). Que convénio poderá existir entre Cristo e Maomé, entre o Filho de Deus e Belial, entre a luz e as trevas, entre o anho e o lobo, entre o fiel e o infiel, entre o cristão e o mouro? (Seg. Ep. Aos Cor., VI; Tratado De poenitentia, Dist. I, § Sina utem, onde diz Item Nec Christus; Causa XXXIII, questão I, cap. Non satis).

\footnotetext{
19 LE GOFF, Jacques. Uma Longa Idade Média. Rio de Janeiro: Civilização
} Brasileira, 2008, pp. 91-115. 
[...] ao tires, pois, o cinto da tua milícia, antes de os sarracenos sucumbirem à tua vitória em Cristo (Decretais, Tit. De renuntiatione, cap. I), nem sejam os teus soldados licenciados sem realizarem a sua missão (Código, De his qui non impletis stipendiis, lei II, liv. X), e sem destruírem os despojos do inimigo (Liv. da Sabedoria, XI; Causa XXIII, questão VII, cap. II). ${ }^{20}$

Aqui é interessante relembrarmos da trajetória ibérica como um elemento determinante no estabelecimento de uma cultura própria a castelhanos, portugueses, aragoneses, etc. O combate lhes está enraizado, modelando inclusive uma diferença com relação às demais soberanias cristãs latinas:

O teu reino [de Alfonso XI] há-de sobrepujar os outros, porque tu, defensor dos outros reinos católicos, verdadeiramente confessar o Criador das nações. Qual dos outros reis fiéis expõe a vida pela fé de Cristo? Tu, rei fidelíssimo, tens mais caridade que os outros, tu que ainda há pouco com teu tio materno, o rei de Portugal [Afonso IV - a referência que se segue diz respeito a Batalha do Salado, ocorrida em 1340; este texto começa a ser redigido um ano depois, em 1341], expuseste a vida pela fé católica. Os outros reis habitam em casas de tecto artesoado, e nadam em delícias; tu vives nas tendas do arraial de Cristo, contente com alimento frugal. Esses dormem e dormitam; tu passas as noites insone, para que a Igreja tua mãe aumente e viva em paz (na Autêntica, Vt iudices sine quoquo suffragio

${ }^{20}$ EdR, Vol. I, pp. 10-11. 
fiant, no princípio da Colação II; Decretais, De restitutione spoliatorum, cap. Frequens, do Livro VI; e no proêmio do mesmo livro VI). Os outros reis louvam a Deus com palavras; tu expões o teu corpo por Ele. Não há rei que se ofereça a morrer por Cristo; só tu levas a gratidão, ao ponto de por Ele derramares teu sangue, como Ele por ti derramou na cruz (João, XIX). Em boa verdade, o teu reino ultrapassa tanto os reinos das outras nações quanto mais te expoões pelo Rei do céu e da terra. [... $]^{21}$

Castela, Portugal e os outros reinos ibéricos (mais Castela, segundo o fervor de Álvaro) são a muralha que impede o Islã de avançar e engolir a Cristandade. Este dado particular gera inúmeras singularidades na própria constituição do rei peninsular. De maneira geral, o ofício de armas é algo que tende a diminuir na figura régia; é o que podemos ver, por exemplo, novamente no tocante ao soberano de França, onde a distinção entre preu homme (homem valente, guerreiro excelente) e prudhomme (homem corajoso e fidalgo - o que caracterizaria mais São Luís segundo fontes da época ${ }^{22}$ ) é visível e é gestada em decorrência das transformações no próprio cenário da Cristandade: a Trégua de Deus e a Paz de Deus, a institucionalização da Cavalaria e a penetração de elementos religiosos na mesma, o direcionamento dos excessos em combate à Terra Santa... Todos

\footnotetext{
${ }^{21}$ EdR, Vol. I, pp. 22-23.

${ }^{22}$ NETO, Jônatas Batista. História da Baixa Idade Média (1066-1453). São Paulo: Editora Ática, 1989, pp. 78.
} 
elementos conduzidos pela Igreja (ou que dela sofrem algum tipo de influência) e que tem como finalidade regular a sociedade - atingindo assim a própria dimensão cultural.

O caráter guerreiro (atrelado ao cristianismo, que permeia a tudo e é comum a todos), portanto, faz parte da cultura e da identidade dos ibéricos, de certa forma sendo "permitido" pela regulação eclesiástica. Entretanto, o mundo está mudando, como já dissemos. Os campos são intensamente cultivados, o comércio e a circulação de moedas florescem, as cidades se expandem... E as monarquias começam rudimentarmente a se institucionalizar. Os reis que vão a campo lutar contra o infiel, Alfonso XI e Afonso IV - para nos atermos ao nosso recorte - precisam ter outra dimensão que condiga com a centralização do poder em suas mãos. Esta dimensão pode ser definida então com a do "legislador". Neste sentido, Álvaro Pelayo e outros homens de saber aqui representam uma peça bastante importante construindo, ao menos teoricamente, um soberano que responda às novas exigências, mas, no caso de clérigos como o é o próprio Álvaro, atentando-se para que aqueles não deixem de se adequarem ao quadro de ordem da Cristandade - ou seja, presidida pelo Sumo Pontífice ${ }^{23}$. Os elementos que estes indivíduos hão de agregar a tal perfil condizem muito com a expansão dos saberes, marca do Renascimento do Século XII,

\footnotetext{
${ }^{23}$ Ver nota 7.
} 
refletindo-se muito bem nos tratados de boa governança, como o são os espelhos de príncipe.

A contenção dos impulsos e desejos, as boas maneiras no comportamento, em suma, aquilo que exigem as quatro virtudes cardeais e suas declinações são um ótimo indicativo de como a cultura cristã perpassa tal conjuntura e é determinante ao conferir elementos para uma nova identidade aos reis cristãos de maneira geral. $\mathrm{O}$ mesmo rei que combate, tomando Álvaro e o caso ibérico, é o rei que deve ser sábio, revelando aqui apenas uma de outras facetas: "Por conseguinte, a intenção do rei, juiz e legislador, deve tender a que os súbtidos vivam segundo a virtude. Para tanto, valem muito a doutrina e a erudição, cabendo, por isso, aos reis o ensinar [...]" e mais a frente sobretudo,

[...] Vós, reis, que julgais a terra, não vos contristeis, mas entendei e instruí-vos. Efectivamente, convém que vós estejais sob o poder d'Aquele de quem vem o entendimento e a erudição, e convém também que não domineis ao acaso como aqueles que a ninguém se julgam sujeitos, e sirvais o Senhor de todas as coisas, isto é, Cristo. $[\ldots]^{24}$

Neste último trecho, é importante que reparemos na finalidade desta sabedoria que o soberano deve possuir, voltando-se sempre para fins últimos ligados a espiritualidade e a Bem-Aventurança eterna. A

${ }^{24}$ EdR, Vol. I, pp. 96-97; Vol. I, pp. 104-105. 
cultura greco-romana (devidamente cristianizada) também se faz determinante neste outro extrato, juntamente com Salomão:

Porque, porém, em todas as coisas susoditas se requer sabedoria ou prudência, são principalmente os reis induzidos, na Sagrada Escritura, ao amor e estudo da sabedoria. Por isso, Salomão não pediu ao Senhor nem riquezas, nem muitos dias, nem as vidas de seus inimigos, mas sabedoria para reger o povo, o que também agradou ao Senhor ( $3^{\circ}$ livro dos Reis, III). Daqui também Boécio dizer, no $1^{\circ}$ livro $D a$ consolação, dirigindo-se à Filosofia: 'Portanto, foste tu quem formulou, pela boca de Platão, este pensamento: que felizes serão as repúblicas, se as regerem os estudiosos da sabedoria, ou se tiverem a fortuna de os seus regedores a esta se aplicarem'. E Valério Máximo diz o mesmo no livro 7.․ Pelo que se chamava século de oiro àquele em que o governo estava confiado aos sábios - diz Séneca na Epístola 92. . E no Policarpo, livro 4. ${ }^{\circ}$, diz-se: 'Não me lembro de os imperadores e generais romanos serem iletrados, enquanto a sua república floresceu. E sei que, desde que a virtude das letras feneceu nos príncipes, entrou de enfraquecer a mão da milícia armada, e o seu principado, como uma raiz cortada cerce'. $[\ldots]^{25}$

Através destas colocações, vemos um novo rei para novos tempos, conforme salientamos no subtítulo; um rei que coliga elementos de uma cultura cristã (e greco-romana também, cristianizada ao longo da Idade Média) sempre presente e quase transcendente com

${ }^{25}$ EdR, Vol. I, pp. 100-101. 
elementos de uma tradição guerreira, atrelada a Reconquista e a elementos próprios de sua conjuntura, como o é a centralização do poder e também o renascer dos saberes representado pela expansão e difusão, bem como na necessidade de sua captação e integração com tal centralização. Estes elementos levam o soberano a ter outra postura com relação à sua realidade - um rei voltado para o bem comum, e por isso instruído e exemplar (conforme os últimos extratos apontam), mas ao mesmo tempo, versado no ofício das armas (sobretudo no caso ibérico) porque a condição de reino fronteiriço e muralha da Cristandade fazem disso uma necessidade. Mais do que um homem moderno sendo aqui gestado, vemos um homem com preocupações e elementos puramente medievais, ressaltado principalmente pela sua identidade e cultura, ambas interligadas.

Para completar nosso raciocínio e evocar novamente a primeira parte deste texto, coligando-a com o restante, podemos ver também o modo como o tratado de teoria política pelagiana, aparentemente encerrado apenas em sentenças e conselhos de governança pode ir além do que vemos na superfície e trazer elementos que nos ajudam a ir um pouco mais a fundo no tocante a estes homens e a estes contextos históricos. Peculiaridades que sondadas devidamente nos permitem atingir, mesmo que minimamente, um vislumbre das ideias e intenções que estão por trás de cada uma destas figuras. 
$\mathrm{O}$ estudo das identidades aqui pensado junto à história e à cultura nos auxilia a compreender as intenções do Bispo de Silves e, num âmbito maior, a conjuntura de transição que marca profundamente a Baixa Idade Média e principalmente, os séculos XIV e XV. Assistimos através de Álvaro o eclipse do poder pontifício frente a ascensão do poder régio, mas as formas como aquele primeiro ainda resiste, sutilmente, usando-se de instrumentos bastante válidos cujo impacto poderia ser decisivo: o apelo ao passado comum que une um conjunto de indivíduos ou, toda uma tradição cultural que torne possível caracterizar este mesmo grupo de indivíduos (ou uma parcela dele, dado que estamos trabalhado aqui com os estamentos mais elevados da sociedade) e orientá-los de acordo com os parâmetros de uma sociedade idealizada que cumpra com os propósitos de um clérigo defensor do poder espiritual: toda a Res Publica Christiana sob a égide do Sumo Pontífice - muito embora tal pretensão comece a ser relegada às brumas do tempo.

\section{Bibliografia}

BATISTA NETO, Jônatas. História da Baixa Idade Média (10661453). São Paulo: Editora Ática, 1989.

BURCKHARDT, Jacob. A cultura do Renascimento na Itália: um ensaio. Brasília, DF: Ed. da UnB, 1991. 
Comissão Executiva das Comemorações do V Centenário da Morte do Infante D. Henrique. Monumenta Henricina (vol. I). Coimbra: Atlandida, 1960, pp. 230-234.

ELIAS, Norbert. O processo civilizador: formação do Estado e civilização. Rio de Janeiro: Zahar, 1993, pp. 193-249.

FERNANDES, Fátima Regina. Teorias políticas medievais e a construção do conceito de unidade. In: História. São Paulo, no 28 (2), 2009.

FRIGHETTO, Renan. Hispania Misera Effecta: a Batalha do Guadalete (711) e a passagem da Antiguidade Tardia à Idade Média. In: GUIMARÃES, Marcella Lopes. Por São Jorge! Por São Tiago! Batalhas e narrativas ibéricas medievais. Curitiba: Editora da UFPR, 2013, pp.19-48.

GUIMARÃES, Marcella Lopes. Cultura na Baixa Idade Média. In: GIMENEZ, José Carlos (Org.). História Medieval II: A Baixa Idade Média. Maringá: EDUEM, 2010, v. II p. 113-136.

LE GOFF, Jacques. Uma Longa Idade Média. Rio de Janeiro: Civilização Brasileira, 2008.

LOMAX, Derek William. La Reconquista. Barcelona: Crítica, 1984.

NOGALES RINCÓN, David. Los espejos de príncipes en Castilla (siglos XIII-XV): un modelo literario de la realeza bajomedieval. In: Medievalismo: Boletin de la Sociedad Española de Estudios Medievales. Ano 16, n 16. Madrid, 2006, pp. 09-39.

O'CALLAGHAN, Joseph F. La cruzada de 1309 em el contexto de la Batalla del Estrecho. In: Medievalismo, 19, 2009, p. 246. 
The Gibraltar Cruzade: Castile and the Battle for the Strait. Philadelphia: University of Pennsylvania Press, 2011.

PAIS, Álvaro. O Espelho dos Reis (Speculum Regum). Vol. I-II. Lisboa: Instituto de Alta Cultura, 1955-1963.

SOUZA, Armindo de. "1325-1480". In: MATTOSO, José (dir.). História de Portugal: A Monarquia Feudal (vol. II, 1096-1480). Lisboa: Editorial Estampa, 1993. 